\title{
A Virtual Community of Practice Framework to Support Doctors' Practices in National Health Insurance (NHI) in South Africa
}

\author{
Alfred Coleman \\ School of Computing, University of South Africa, South Africa \\ Telephone/ Mobile: 0027124296395/0027731370859,E-mail: colema@unisa.ac.za
}

KEYWORDS Virtual. Community. Practice. National. Health. Insurance. Healthcare Services. Computer Mediated

\begin{abstract}
The introduction of National Health Insurance (NHI) in South Africa poses major challenges to doctors in rural communities who serve high number of patients daily. This paper investigated how doctors in rural hospitals in South Africa use Virtual Community of Practice ( $\mathrm{VCoP})$ to share experience with specialist doctors to improve on their practices. A case study approach was used. Ten doctors were selected from ten hospitals in the North West Province. Data was collected using semi-structured open- ended interview questions to inquire about availability of ICT infrastructure, doctors' workload, methods and frequency of consultation, task type, and satisfaction of using computer-mediated tool. Findings revealed that an average of 15 consultations per doctor to a specialist doctor per week was done through face- to- face or telephone conversation. The results led to a proposed VCoP Framework based on the principles of responsibility, connectedness and reverence to assist doctors render quality healthcare services under the NHI project.
\end{abstract}

\section{INTRODUCTION}

Many countries in Africa experience a serious shortage of medical professionals, particularly specialist doctors. The problem is exacerbated by the high emigration of African doctors for better prospects overseas. Those who remain and practise in rural communities experience isolation due to distance. They treat high number of patients per week and are required to be generalists addressing a wide range of issues, and thus becoming mini-specialists to treat patients' specific conditions (Stamm et al. 2002). However, the frequency of attending to any one condition becomes low, making it difficult for these doctors to maintain a broad current level of knowledge and best practices (Weeg et al. 2004).

With the advent of the NHI in South Africa, the government aims to provide quality healthcare service to every citizen irrespective of their financial position or personal contributions to the NHI scheme (Ataguba and Akazili 2010). This will put enormous pressure on doctors in rural communities to provide services to many more patients, and therefore exacerbating the existing legacy of high number of patients to a doctor ratio (1 doctor to 18000 patients) in rural hospitals (Coleman 2011). Doctors in rural hospitals therefore, need to communicate with specialist doctors at urban hospitals to seek professional ideas to improve their practices in order to meet the challenges of the NHI. The rationale for such communication is that many of the doctors placed in rural communities are general practitioners who experience isolation due to distance; and therefore, need specialist doctors to share professional ideas with (Stamm et al. 2002). However, knowledge sharing is intangible and tacit in character (Ardichvili et al. 2003). Tacit knowledge resides with an individual and it is knowledge that is understood without being stated (Biggam 2001). As a result one of the methods to help doctors share and internalize knowledge is to allow participatory sharing of their experiences (Ardichvili et al. 2003).

Therefore, the introduction of the NHI as a means to provide quality healthcare service to every citizen can be achieved by utilizing VCoP as a tool to improve professional practice through knowledge sharing. This is indicated by Wenger et al. (2002) who emphasize that the $\mathrm{VCoP}$ is an informal, self-organizing network of people that are dedicated to sharing knowledge. An important characteristic of VCoP is that members help one another to answer questions and solve problems. In this way they share and create knowledge (share information and good practices).

\section{Objective of the Study}

This paper investigated how doctors in rural hospitals share professional knowledge with specialist doctors at urban hospitals and based on the findings proposed a VCoP Framework to support the NHI project in South Africa. The 
rest of the paper is presented as follows: related work, methods, results and discussion and the proposed VCoP Framework.

\section{Related Work}

Community of Practice (CoP) is defined as "peers in the execution of real work, held together by a common sense of purpose and a real need to know what each other knows" (Brown and Duguid 1998). Again, Wenger and Snyder (2000) define CoP as "groups of people informally bound together by shared expertise and passion for a joint enterprise". Other key definitions of CoP include knowledge sharing and learning, a common practice or solving of common problems by members of a group and the construction of a common knowledge repository (Wasko and Faraj 2000; Schultze and Orlikowski 2001). CoP was initially considered to be predominantly a situated learning or co located learning (Wasko and Faraj 2005). However, the spread of technology and globalisation has resulted in the emergence and development of virtual only CoP. VCoP facilitates the sharing of real and particularly tacit experience by enabling people with common interests and objectives to engage in discussion, debate, and reflection through the web (Murillo 2008; Rogers 2000; Thomas 2005). VCoP is computer-mediated tool. Types of VCoP include Internet message board where people can discuss thoughts or ideas, online chat rooms where members communicate and exchange ideas in real time and social network services where the website allows people to connect and look for support from peers and acquaintances (Quan and Young 2010). This paper is based on VCoP using social network services which are rooted in textual communication.

A vital component of $\mathrm{VCoP}$ is textual communication which refers to how participants in virtual environments create, affirm, or change shared meaning and culture by using text. Hermeneutics, the 'study of interpretation, especially the process of coming to understand text' (Boland 1991: 439) provides an ideal framework for analysing and understanding the activities and significance of online places inhabited by communities of writers and readers of the shared texts that form the basis of their interaction. The mechanisms of interpretation are the means through which online places are able to create robust cultural environments.

\section{METHODS}

The study was carried out in the North West Province of South Africa.Ten community hospitals (Taung, Ganyesa, Revilon, Boemhof, Kerkledrop, Rustenburg, Christiana, Boitumelong Empilisweni and Classic House hospitals) were purposefully selected. These hospitals were selected based on their geographical locations which span across the entire province and form part of the government owned institutions in South Africa.

The participants for the study were drawn from the entire population of doctors in the ten hospitals. In describing population, Polit and Beck (2008) indicate that it is the aggregate of cases having a common and designated criterion that is accessible as subjects for a study. A purposive sampling technique was used in recruiting participants from the population of doctors. A doctor from each of these hospitals was selected. The participants were selected by their profession which was relevant to the study. Ten doctors volunteered to participate in the study.

Data was collected using semi-structured open -ended interviews. The interviewees represented different roles ranging from specialist doctors to general practitioners. The interviewees were asked to tell in their own words the average number of patients served per week, processes in consultation with other doctors, communication practices using computer-mediated tool, and the satisfaction using computer-mediated tool. The interviews lasted for three hours with each interviewee and were audio-recorded and transcribed by the researcher.

Integrity of data entry from the study was checked by another researcher. Transcripts were coded using Wolcott's (1994) methods of case study analysis techniques. After the initial coding, broad categories were identified by searching for patterns in the participants responses. The categories were ICT infrastructure availability, doctors' workload, methods of consultation among doctors, frequency of consultation, task type, and satisfaction of using computermediated tool.

\section{RESULTS AND DISCUSSION}

The results and interpretation from the interviews are presented under the categories of ICT infrastructure availability, doctors' work- 
load, methods of consultation among doctors and frequency of consultation, task type and the satisfaction of using a computer mediated tool. These categories are discussed below.

\section{ICT Infrastructure Availability}

The findings revealed that there are ICT equipment like computers, fax machines, telephones, scanners and Internet connections in the hospitals. Most of the computers were found in the outpatient department (OPD) and in the accounts department. It was found that the computers in the doctors' consultation rooms were not used for clinical duties. Computers in the hospitals were rather used by the administrative staff for capturing patients' demographic information and for revenue collection. It was also noted that Internet connection in the hospitals was very slow and often down for two to three times per week.

The poor infrastructure restricted doctors from sharing their professional ideas through the use of VCoP which can assist "doctors in the execution of real work, held together by a common sense of purpose in a real need to know what each other knows" (Wasko and Faraj 2005). The implementation of VCoP will facilitate the sharing of tacit experience by enabling the doctors with common interest and objectives to engage in discussion, debate and reflection of their professional practices through the web (Murillo 2008; Rogers 2000; Thomas 2005).

\section{Doctors' Workload}

It was noted that the average size of the rural hospitals has a direct link with the number of doctors deployed in the hospitals. The average number of doctors of each rural hospital is three doctors per hospital. Each of these doctors serves an average of 18000 patients per month. Ninety percent of these hospitals do not have specialist doctors and most cases which require specialist doctors are referred to the provincial or national hospitals.

There are a high number of patients in rural hospitals whose nature of illness requires specialist attention and this puts enormous pressure on doctors in rural hospitals to consult with specialist doctors for professional advice. These patients exclude those who have been admitted to the wards. Therefore, doctors can use differ- ent types of VCoP such as Internet, message board and online tools to discuss ideas with their counterparts and specialist doctors on how to handle such cases (Quan and Young 2010).

\section{Methods of Consultation and Frequency of Consultation Among Doctors}

Consultation by doctors from different hospitals is done through face-to-face methods at scheduled meetings. Consultation is also done through telephones and short message services (SMSs). An average of 15 consultations between a doctor and a specialist doctor through faceto-face or telephone per week was revealed during the interviews. Issues regarding doctor to doctor social consultations were done through cell phones and it was frequent. Since holding face- to- face interaction on regular basis can be costly and time consuming, online community of practice supported by internet technologies can be a viable alternative to life conversation and knowledge sharing (Dubé et al. 2005). Furthermore, Murillo (2008) indicates that VCoPs can facilitate the sharing of real tacit experience by enabling doctors with common interests and objectives to engage in discussion, debate, and reflection.

\section{Task Type}

It was noted from the interviews that doctors in rural hospitals perform numerous tasks which require them to seek professional assistance. These tasks include dental, physiotherapy, occupational therapy, oncology, psychological counseling, x-ray, dietetics, pharmacy, speech therapy and social services. Despite the wide range of services which these hospitals offer, there are no computer-mediated tools like e-consultation, e-referrals, e-prescription, and e-patient record which can assist the doctors to seek professional help in their clinical duties.

However, the use of VCoP could provide a common practice or solving of common problems of doctors and help them construct a common knowledge repository to improve the various tasks carried out in the hospitals (Schultze and Orlikowski 2001). An important component of VCoP is textual communication (Boland 1991). Therefore, a knowledge repository based on textual communication will provide an ideal framework for analyzing and understanding of activities of participating doctors. 


\section{Doctors' Satisfaction of Using a Computer-mediated Tool}

All the doctors $(n=10)$ interviewed expressed their dissatisfaction about the absence of (VCoP). Again the doctors expressed that those consultations which involve the sending of patients' images such as X-rays and pathological images for professional opinion were difficult to transmit because of poor and slow Internet connectivity and lack of software application.

The use of VCoP which depends largely on textual communication to provide understanding to participants (doctors) in the virtual environment (Boland 1991) could assist doctors in rural hospitals to exchange and share professional ideas. Again the usage of VCoP by doctors creates a bond of togetherness for mutual service (Schultze and Orlikowski 2001) which leads to improvement of job satisfaction.

\section{The Need for VCoP Framework to Support NHI}

Based on the findings, this paper proposes a social framework as a guide to the VCoP. The social framework is based on three principles: responsibility, connectedness and reverence which are social structures influencing the vir- tual communication processes. Responsibility refers to the fact that designers of the VCoP need to identify specific incentives to motivate doctors to provide quality and continuing input into the VCoP whilst those asking for consultation need a reason to provide follow-up services. Doctors need to take ownership and accountability of the VCoP. Connectedness refers to the social elements that engage doctors to adopt the system in the first place and to turn to it when they seek new information and help. Reverence refers to the relationship between doctors on this VCoP system to accord respect to other users. This is where participants located in different parts of the world explicitly take into consideration the broad cultural and resource differences of other doctors when facilitating communication among the users. Figure 1 represents the proposed VCoP framework for doctors in the NHI project.

The innermost ellipse represents the process of communicating with text. This refers to the recording of activity by virtual community members who are the doctors. The interpretation of text is dependent upon the context in which it is written. In other words, to interpret or ascribe meaning, the text must be situated within a multi-faceted context (Geertz 1983). This context is understood by investigating the relations

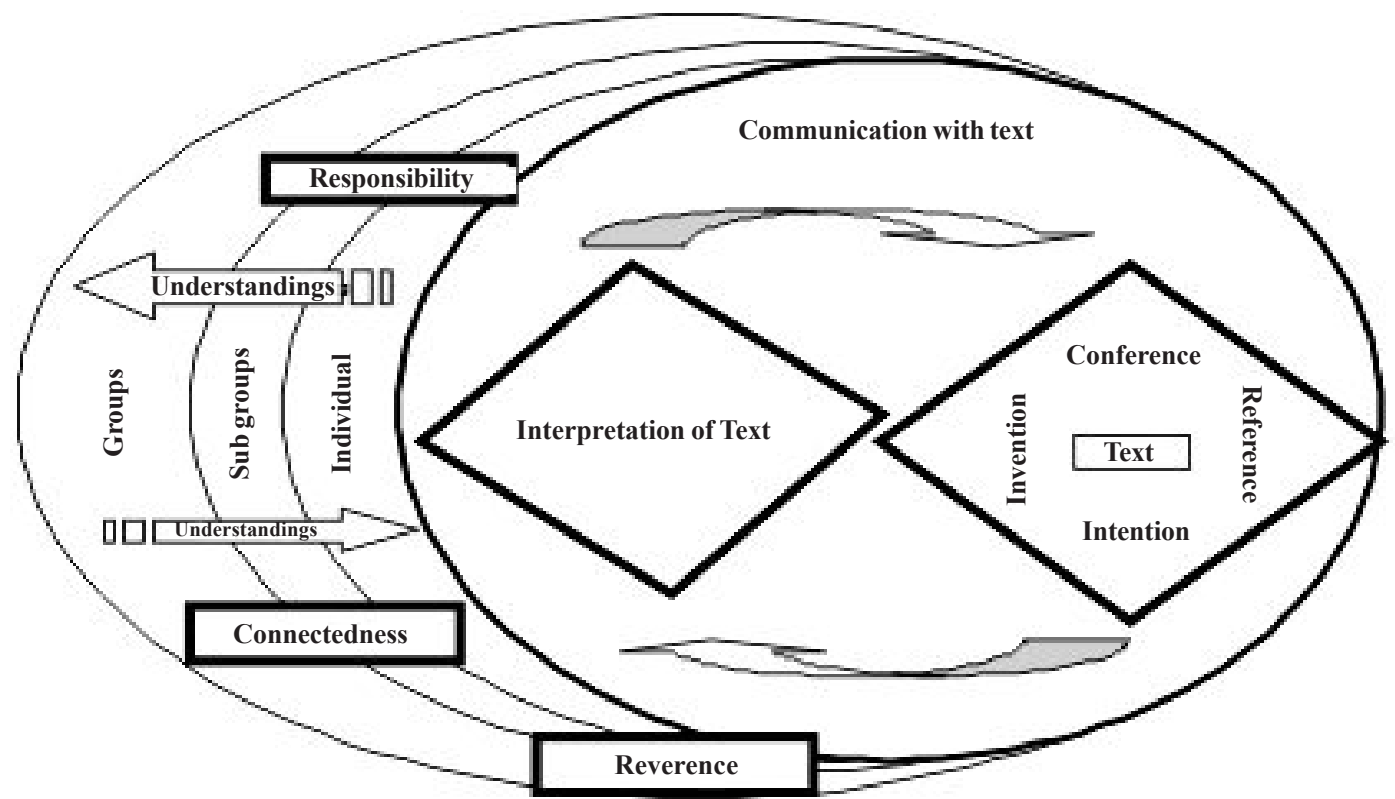

Fig. 1. Virtual community of practice framework for doctors in NHI Project 
of the text to various contextual facets (Becker 1979). Four important contextual relations as indicated in the framework are: coherence (the relation of textual units to other textual units in the text) describes the set of constraints or rules that govern the creation of text by doctors, enabling other readers to make sense of them; invention (the relation of text to associated texts) measures the social readability of texts in relation to the rules and body of knowledge established by earlier texts; intention (the relation of text to its creator or creators) describes the purpose for which a text is created; and reference (the relation of text to non-literary events) describes the ways in which events and objects in the world enter into the discourse of the community (Becker 1979; Geertz 1983). In this VCoP Framework, information exchange is intertwined with socializing principles (responsibility, connectedness and reverence) to promote knowledge sharing by doctors.

This VCoP Framework is to assist doctors rendering healthcare services to the NHI project to share professional knowledge to improve the delivery of healthcare services to rural communities in the North West Province and South Africa as a whole. Doctors can enter case information in the form of text or images and send or assign the case to a specialist doctor in one of the urban hospitals for advice. Again the connectedness will assist doctors in rural hospitals, where possible, to contact Diaspora South African doctors in overseas for assistance.

\section{CONCLUSION}

Having reviewed the problems associated with VCoP by doctors in rural hospitals in the North West Province, unpacked the concept of VCoP, investigated ICT infrastructure, doctors workload, task type and doctors dissatisfaction of poor community of practice, it was revealed that the adoption of VCoP for sharing of professional ideas towards solving clinical issues and task assignments by doctors are strongly affected by slow emails, slow servers and constant outages of electricity power supply in rural hospitals. These challenges do not only affect community of practice but also prevent the implementation of any other e-health services like e-prescription or e-referral. In conclusion, this paper has offered a new approach to VCoP Framework based on responsibility, connected- ness and reverence to support doctors in rural hospitals to deliver effective healthcare services under the new NHI project in South Africa.

\section{RECOMMENDATIONS}

Based on the findings of this paper it is recommended that the proposed VCoP Framework which is based on responsibility, connectedness and reverence be implemented to assist doctors in rural hospitals. Again the installation of stand by generators for electricity supply to rural hospitals for use during power outages should be considered as well as the provision of high speed Internet connectivity.

\section{REFERENCES}

Ardichvili A, Page V, Wentling T 2003. Motivation and barriers to participation in online knowledge-sharing communities of practice. Journal of Knowledge Management, 7(1): 64-77.

Ataguba JE, Akazili J 2010. Health care financing in South Africa moving towards universal coverage. The South African Journal of CPD, 28(2).

Becker AL 1979. Text-building, epistemology, and aesthetics in Javanese shadow. In: A L Becker, AA Yengoyan (Eds.): The Imagination of Reality: Essays in Southeast Asian Coherence Systems. Norwood, NJ: Ablex, pp. 211-243.

Biggam J 2001. Defining Knowledge: An Epistemological Foundation for Knowledge Management. Proceedings of the $34^{\text {th }}$ Hawaii International Conference on System Sciences. In Computer Society Press, Maui Hawii, January 3 to $6,2001$.

Boland RJ 1991. Information system use as a hermeneutic process. In: H E Nissen, H K Klein, R Hirschheim (Eds.): Information Systems Research: Contemporary Approaches and Emergent Traditions. Amsterdam: Elsevier Science Publishers B.V., North Holland, pp. 439-458.

Brown JS, Duguid P 1991. Organisational learning and communities of practice: Toward a unified view of working, learning and innovating. Organization Science, 2(1): 4057 .

Coleman Alfred 2011. Developing an e-Health Framework through Electronic Healthcare Readiness Assessment. $\mathrm{PhD}$ Thesis, Unpublished. Port Elizabeth: Nelson Mandela Metropolitan University.

Dubé L, Bourhis A, Jacob R 2005. The impact of structuring characteristics on the launching of virtual communities of practice. Journal of Organizational Change and Management, 18(2): 145-166.

Geertz C 1983. Local Knowledge: Further Essays in Interpretive Anthropology. New York, NY: Basic Books.

Murillo E 2008. Searching usenet for virtual communities of practice: Using mixed methods to identify the constructs of Wenger's theory. Information Research, 13(4): 386.

Polit DF, Beck CT 2008. Nursing Research: Generating and Assessing Evidence for Nursing Practice. Philadelphia: Lippincott Williams \& Wilkins. 
Quan HA, Young AL 2010. Uses and gratification of social media. A comparison of facebook and instant messaging. Bulletin of Science Technology and Society, 30: 350361 .

Rogers J 2000. Communities of practice: A framework for fostering coherence in virtual learning communities. Educational Technology and Society, 3(3): 384392.

Schultze U, Orlikowski WJ 2001. Metaphors of virtuality: Shaping an emergent reality. Information and Organization, 11(1): 45-77.

Stamm BH, Varra EM, Pearlman LA, Giller E 2002. The Helper's Power to Heal and To Be Hurt or Helped - By Trying. Register Report. Washington, DC: A Publication of the National Register of Health Service Providers in Psychology.

Thomas A 2005. Children online: Learning in a virutal community of practice. E Learning, 2(1).

Wasko M, Faraj S 2000. It is what one does: Why people participate and help others in electronic communities of practice. Journal of Strategic Information Systems, 9(2): 155-173

Wasko M, Faraj S 2005. Why should I share? Examining social capital and knowledge contribution in electronic networks of practice. MIS Quarterly, 29(1): 35-57.

Weeg SC, Stamm BH, Cutler K, Cunningham BJ 2004. What can we do for continuing education for rural health professionals? Virtual grand rounds. Telehealth Practice Report, 9: 3-8.

Wenger E, Snyder WM 2000. Communities of practice: The organizational frontier. Harvard Business Review, 78(1):139-145

Wenger E, McDermont R, Snyder W M 2002. Cultivating Communities of Practice. Harvard Business School Press, Boston, MA.

Wolcott HF 1994. Transforming Qualitative Data: Description, Analysis, and Interpretation. Thousand Oaks, CA: Sage. 